\title{
DIE WORTELS EN KENMERKE VAN DIE TRADISIONELE AFRIKAANSE LEWENSTYL
}

In ons tydsgewrig kan dit moontlik vreemd opklink om by ' $n$ akademiese fees te begin met ' $n$ verwysing na ' $n$ Bybelwoord, maar hier, vandág, waar ons die honderdste bestaansjaar feestelik gedenk van 'n hoëronderwysinrigting wat onbevange in sy naamvaandel die stempel "Christelik" dra, sal dit niemand verbaas as ek my relaas vanmore plaas onder ' $n$ Bybelteks nie:

Matt. $7: 16$ - ..'n Mens pluk tog nie druiwe van dorings of vye van distels nie?

Matt. 12:33 - Julle moet of die boom goed maak en sy vrugte goed, of julle moet die boom sleg maak en sy vrugte sleg; want aan sy vrugte word die boom geken.

Ek herhaal: Want aan sy vrugte word die boom geken.

Dis my opdrag om met $\mathrm{u}$ te gesels oor die wortels en kenmerke van die tradisionele Afrikaanse lewenstyl. Daarvoor is dit nodig dat ons eers twee begrippe van nader bekyk en oorweeg: die eerste is

\section{Lowenstyl}

Ons merk dadelik dat dit saamgestel is uit lewe en styl; en verder dat die twee woorde verbind is met ' $n$-s-, waardeur ons in staat gestel word om die samestelling verhelderend om te stel as: styl van die lewe.

Styl is in ons verband ' $n$ hoogs prikkelende woord. Dit hang saam met 'n ou Germaanse wortel of stam: sti-, wat beteken styf, stewig, hard. Dié stam word uitgebrei d.m.v. verskillende uitgange, waarby nog klinkerwisseling aangewend word, sodat ons uiteindelik 'n hele woordgeslag kry wat gesamentlik die oer-grondbegrip voortdra: staan, steen, stand, stad; star, staar; stok, staak, steeks; staf, styf, stewig; stel, staal, stol steel of stingel; en dan styl - waarby ook aansluit die Latynse stilus.

Dis nie my taak of voorneme om dié woordfamilie in al sy divergensies in ons taal te volg nie. Genoeg om te sê dat styl in sy wortel die betekenis het van styf, stewig, sterk. In 
die samestelling lewenstyl moet dit dan beteken: iets wat aan die lewe styl gee, stewigheid, standvastigheid, vorm soos die onderstel van 'n kar. Ons kan dit verder deurtrek en sê: Styl in die samestelling lewenstyl beteken dan die geraamte of raamwerk waaromheen die lewe hang, of waaromheen dit saamgeweef is tot eenheid. Net soos die onderstel vorm gee aan die kar, die geraamte aan die liggaam, die raamwerk aan die huis, die skering aan die weefsel, net so is die styl die ding wat die vorm is van ons lewe - jy kan maar sê, soos die Fransman: „Styl, dis tog die ganse lewe, die ganse mens". In hierdie sin praat ons van die styl van Pierneef, Rembrandt, Mikro, Van Melle. By die skrywer is dit seer sekerlik nie die vraag hoe hy sy kommas en punte aanwend nie, maar die vraag hoe sy hele menslikheid tot openbaring gebring word in die geskrewe woord. En dít is die eintlike opdrag vanmore: Hoe die Afrikaanse mens se hele wesensaard tot stand gekom het, in stand gehou word, en voortdurend tot uiting kom in sy lewenswyse.

Die tweede woord van betekenis in ons opdrag is:

\section{Tradisionele}

Die twee woorde wat die meeste holrug gery word deur openbare redenaars en die meeste onderwerp word aan wanvoorstelling en verdraaiing en onbegrip, is ongetwyfeld die siamese tweeling kultuur en tradisie. Die woordeboekverklaring van tradisie is redelik onskuldig genoeg:

(1) „Die oordra van geslag op geslag, mondelings of in skrif, van geestelike besittings;

(2) die navolging van vaste, oorgelewerde gebruike, menings, gevoelens, beginsels, ens." (HAT).

Dis presies wat dit is. Maar as ons om ons heenkyk na wat in koerant, boek en tydskrif aan dié begrip gehang word, as ons luister na ons opstandige jeug, as ons ag slaan op ons harige jongmanne en ons dogters met hulle beloof-jou-niksrokkies, dan moet tradisie so 'n soort skelwoord wees, 'n onaangename woord wat beteken: hand van die dood, muf, afgestorwe, noags, geestelike remskoen. En iemand wat hom aan die volkstradisie hou, is vir diesulkes 'n versuurde brompot, 'n jammerlappie wat vogtig en ongeurig alle pret en 
jolyt en vooruitgang doodlê - 'n ware verkrampte, om u eie woord uit Potchefstroom in sy regte verband te gebruik!

Daar is ewewel 'n ander opvatting van tradisie, nl.: dié sedes, gebruike en beginsels wat van die een geslag op die ander oorgelewer word op so 'n wyse dat dit die volgende geslag se lewenswyse rig, lei en beveilig. Maar die oorlewering geskied telkens so dat die volgende geslag hom daarby aanpas, en gelyktydig die tradisionele omvorm om draer te word van die eietydse opvattings en behoeftes. Só gesien is 'n volk se tradisie 'n geestelike lewensproses waarin die huidige vormend en aanpassend rekening hou met die geesteslewe van die voorgangers, en gelyktydig geestelike ankers en nuwe groeipunte oorhandig aan die nakomelinge. Tradisie is dan 'n verrykende geestesproses wat kom uit die verlede en wat oor die hede in die toekoms reik, en wat allermins daarop bereken is om ' $n$ volksgemeenskap in te deel in verkramptes en verkrimptes.

Maar let op - die grondvereiste is: oorlewering. Dit wil sê voordat daar van tradisie gepraat kan word, moet daar oorlewering wees, moet daar minstens twee opeenvolgende mensegeslagte by so 'n geestesbesit betrokke wees. Dink nou mooi na: Baie van ons wat ouers is, se eie ouers leef nog en help ons eie kinders grootmaak, terwyl ons ons eie kleinkinders hou om gedoop te word. Dit wil sê gesinne wat bestaan uit vier of vyf lewende geslagte - ,tot in die vyfde geslag!" - is in ons tyd haas alledaagse verskynsels. Dus, oupagrootjie wat daar 'n gewoonte van gemaak het om sy dag met Boekevat te begin, dit aan sy seuns geleer het en hálle aan hùlle seuns tot in die vyfde lewende geslag, het 'n tradisie begin, geskep, en het dit beleef dat dit in die ware sin oorlewering geword het. Daarmee wil ek sê: tradisieskepping is nie dood, is nie doods nie, is nie iets van die verlede nie, maar bestaan as lewende geestesproses in ons eie tyd en in ons eie lewens. Ons is selde bewus daarvan, maar almal van ons doen een of ander ding, het een of ander opvatting wat nog deur ons kinders opgeneem sal word of reeds opgeneem is, en wat húlle weer sal voortdra - dis tradisie. En wat daarmee saamhang noem ons die tradisionele.

Is dit muf? Verfoeilik? Dooie hand uit die graf? Verkramp? Of is dit eerder 'n lewensproses wat gesonde volksgroei, ontwikkeling, vernuwing van die oue aan die hand van 
die nuwe bevorder?

Nou kan elkeen van ons vir sigselwers die samekoppeling tradisionele lewenswyse sinryk uitlê en bepeins. Maar dis nog vir ons nodig, as volgende stap in ons betoog, om die samekoppeling, in die lig van ons opdrag, te verleng met ' $n$ derde woord: Afrikaanse tradisionele lewenswyse. Dan kom ons voor die noodsaak om die begrip Afrikaner te omskryf. En nou wil ek my allermins op 'n staatsregtelike grondslag stel. Inteendeel, dit gaan my suiwer en uitsluitend om die kultuurbegrip. Afrikaner is hy wat Afrikaans praat as die wesenlike taal van sy gees, wat hom deur sy aanvaarding van die tradisionele Afrikaanse lewenswyse gevoel as lid van die Afrikaanse volk en daardeur die Afrikaanse volksgeskiedenis, geestelike en stoflike belange aanvaar as sy eie, wat hom die lotgevalle van die Afrikaanse volk in verlede/hede/toekoms aantrek as sy eie lotgevalle, en wat afstammeling is van Europese voorouers wat Suid-Afrika aanvaar het as hulle enigste, blywende geestelike en stoflike tuiste. So beskou beteken dit dat elke mens self moet kan sê of hy Afrikaner is of nie. Verder: Hy wat vra - Wie is die Afrikaanse volk en wie behoort daaraan? - openbaar deur sy vraag dat hý nie lid is van dié volk nie.

Daar was nie altyd Afrikaners nie. Dié mensesoort is 'n historiese kultuurverskynsel wat in Suid-Afrika saamgegroei het uit wat elders vandaan gekom het. En tesame met die saamgroei van mense tot 'n nuwe verskynsel het gegroei sy taal en sy lewenshouding of - tradisionele lewenswyse. Dít moet ons goed verstaan, want ons moet begryp dat daar nie so iets is as om aan 'n groep mense 'n taal op te lê, ' $n$ kultuur of lewenswyse aan hulle af te dwing nie. Die Afrikaanse mens ontwikkel in die geskiedenis tesame met sy taal en sy lewenstyl. Dis 'n drie-eenheid, onlosmaaklik aan mekaar verbind en met mekaar verweef sodat sonder die een die ander nie is nie, nie kan wees nie. Die volk is sy taal, is sy lewenstyl. Die Afrikaanse taal en die Afrikaanse volk moet ons by hierdie geleentheid aanvaar as bestaande eenhede. Die beskrywing van wording en groei daarvan sal ons te ver uit ons koers neem. Ons spits ons toe op die derde bestanddeel: lewenswyse as tradisie, die Afrikaanse tradisionele lewenstyl, alhoewel dit telkemale sal deurskemer dat ons eintlik besig is met ' $n$ identiese drieling: drie enershede in ' $n$ ander vorm. 
Hoedat Cabo de Tormentose geword het tot Cabo de bôa Esperance, is vir ons antieke geskiedenis. Vir ons hier is die betekenisvolle tydstip daar in 1656, toe kommandeur Jan van Riebeeck, met toestemming van Here Sewentien, die eerste halfdosyn Vryburgers aan die rant van die Kaapse Vlakte losgelaat het - losgelaat het uit die bande van diensbaarheid, losgelaat het uit die inenging van die verstolde Middeleeuse gemeenskappe waaruit hulle gekom het, losgelaat het aan die buitenste rant van die groot onmeetlikheid wat Afrika genoem word.

Hy, kommandeur Jan het toe 'n indeling gemaak van ons koloniale samelewing: landbouers, veehouers, en losieshouers met of sonder tapnering tesame met die amptenare en handwerkers. In breë trekke: saaiboere, veeboere, en dorpenaars. Hierdie indeling het tradisioneel geword en dit is eintlik nog die grondliggende indeling van ons Afrikaanse samelewing, al is dit ook so dat die nadruk telkens verskuif het na ' $n$ ander groep, en tans sò verander is dat die twee boerende groepe haas altyd in die verknorsing verkeer.

Kom ons kyk na kommandeur Jan se tydvak aan die Kaap - 'n tydvak van tien jaar. Opvallendste van hierdie tydvak uit ons kykhoek, is die manier waarop daardie vroeë koloniste saamgewoon het. Dis die tydvak van die sogenaamde Fortgemeenskap. Al wat leef en beef, van Europese oorsprong in die tydvak, het onderdak gevind in die fort - die enigste veilige plek. Inderdaad het hulle geleef as een groot gesin. Soos 'n gesin het hulle drie keer daagliks geëet met tafelgebed, en die oggend- en aandmaaltyd is voorafgegaan of gevolg deur Boekevat. En elke fortmens moes aan tafel wees, tensy daar ' $n$ grondige verskoning was. Sondae was daar 'n ekstra byeenkoms van almal vir godsdiensoefening, en weer moes almal aanwesig wees. Ná die Sondagoggenddiens is huwelike gesluit, en die hele fortgemeenskap was gaste.

Van dié groot gesin was kommandeur Jan de wesenlike vader. Van Riebeeck was arts, maar hy het nie sy amp beoefen as kommandeur nie - behalwe by een geleentheid, toe almal, die amptelike "arts" inkluis, die ontstellende gevolge moes verduur van 'n eerste oormatige kennismaking met hotnotsvye. Toe het Van Riebeeck ingegryp en self as arts opgetree. Ons sien hier reeds die patriarg verskyn, wat so kenmerkend is van ons volksvaders. 
En wanneer op 'n verbygaande skip 'n predikant was, was hy altyd die tafelgas van die kommandeur en het gelei by die huisgodsdiens van die hele fortgemeenskap.

Selfs ná vrylating van die Vryburgers moes hulle snags in die fort oornag as gevaar gedreig het, en Sondae was hulle aanwesig by die oggenddiens, by feestelikhede en by ander byeenkomste waar almal se aanwesigheid verlang is.

Ons sien hier dus: gesin - godsdiens - tafelgebed, as grondslag van 'n gemeenskap.

Toe 'n keuse gemaak is van Vryburgers is gelet op: goeie sedelike gedrag, voorbeeldige karakter, en boweal Protestantse Christelikheid. Hierdie maatstawwe is streng deurgevoer tot in 1806 - en met die koms van 'n nuwe bedeling is dit noodsaaklik geag om dit af te skaf. Maar toe was die Afrikaanse mens al iets van die werklikheid, 'n werklikheid wat besonder gou voltrek moes gewees het. Dink aan die intieme saamwoon in die fort en die onmiddellike fortomgewing vir die eerste tien jaar. Daarna geleidelike verskuiwing die Kaapse vlaktes in - noordwes en noordoos. Maar tot 1715 beperk tot 'n gebied wat saamval met die eerste plato: Kaapstad as middelpunt van 'n sirkel met 'n straal van 25 myl. Die eerste berge as kraalmuur, met Vergelegen van die Van der Stels dwars voor die poort wat lei na Caledon - die Oorbergse wêreld. Toe word Vergelegen gesloop, Willem Adriaan word herroep na Holland - en die poort uit die Boland word wawyd oopgelaat. En die trek met die wa oor die berg begin.

En tog wonderlik - ons taal, Afrikaans, toon van die Kaap af tot by die Wolkberge, van die Grootrivier tot aan die $\mathrm{Nyl}$ ' $\mathrm{n}$ grondliggende eenvormigheid wat verstommend en onbegryplik is as ons nie aanvaar dat die sy beslag gekry het voordat die poort oopgegaan het nie. Afrikaans moes al vroeg in die $18 \mathrm{e}$ eeu in hooftrekke aanwesig gewees het, en die verskillende bevolkingsgroepe moes dan al grondliggend saamgesmelt gewees het tot 'n nuwe eenheid waarvan die groei bevorder is deur die omringende gevare van 'n nuwe land, verdrukking van die koloniste deur die amptenare en ' $n$ inperking deur Here Sewentien om stoflike gewin. Ons sien die Franse taal binne ' $n$ enkele geslag verdwyn - en ons hoor 'n nuwe hartklop wat nòg Hollands, nòg Duits, nòg Frans is. Maar ' $n$ nuwe historiese eenheid wat baie lank sonder 'n eie naam so bly. 
Hierdie nuwe kultuurmens stoel op die Vryburgers wat streng godsdicnstig gekeur is, en wat met die Bybel van die Fort de Goede Hoop weggetrek het. En dis die Bybel, meer as enige ander enkele geestesfaktor, wat die lig van die beskawing bestendig laat brand het tydens die wordingsjare van volk, taal en kultuur. Naas die ou Statebybel het die gesinne van destyds ook beskik oor die godsdienstige literatuur van die tyd: Groenewegen, Brakel, De Donderslag der Goddelozen - om maar enkeles te noem.

En so, lesende en trekkende agter weiding en wild aan, ontdek veral die veeboere baie gou 'n ooreenkoms tussen hulleself en die lotgevalle van die Ou-Testamentiese volk Israel. En net so gou groei die opvatting dat dié nuwe mens aan die suidpunt van Afrika 'n tweede Godsvolk is, geroepe om die land te besit en te beskaaf. En die opdragte van Moses aan sy mense, word opnuut opdragte van die nuwe Israel. Dink maar: Julle sal nie dogters van die vreemde volke om julle neem tot vrouens van julle seuns nie, julle sal nie julle dogters gee tot vrouens van húlle seuns nie.

Dit is die lewenstyl van die nuwe mens, die Afrikaner: die Bybel, die hele Bybel, maar veral die Ou-Testamentiese boeke: die Pentateug, Prediker, Jesaja, Job en die Psalms. Dit word soms genoem 'n „praktiese Calvinisme” - wesenlik is dit 'n lewenstyl wat groei uit 'n daaglikse omgang met die Bybel, soseer dat die Bybel nie net die klasboek word van die kind wat leer lees nie, maar die leerboek van die volwassene wat sy weg probeer vind deur die doolgange van die lewe.

Om hierdie gedagtegang ten volle uit te diep sal 'n groot boekdeel verg, en dit sou langer duur as die knap halfuur wat hier tot ons beskikking staan. Genoeg as ons op enkele punte in ons volkslewe wys om die Bybelgrond van ons lewenstyl aan te toon. Die Israeliete kom terug uit die Babiloniese ballingskap. Daar is 'n groot volksametrek, voorraad word opgeneem. Die profeet vind dat baie Israeliete hulle in die vreemde met vreemdelinge vermeng het. Die vermengde gesinne word getel, die name word opgeskryf, die belofte is om vreemde vrouens met hulle kinders weg te stuur. Dit loop uit op 'n volksverbod: sulke gemengdes mag geen aandeel hê aan die godsdienstige verrigtinge nie. Die Afrikaanse volksverhuisers staan noord van die Oranje, hou hulle eerste 
volksbyeenkoms op „eie" grond onder „eie" gesag. Een van die eerste verordeninge: persone van gemengde bloed kan nie sitting hê in die raad van die volk nie - tot in die vyfde en tiende geslag. En hierdie verbod word herhaal in elke nuwe grondwet tot in 1898. In ons eie tyd het dié skeiding uitgegroei tot staatsbeleid en ons weet almal watter rol persone met gemengde afkoms in ons samelewing toegelaat word.

Die goddelike opdrag aan Israel: wees verdraagsaam teenoor die vreemdeling in julle midde, want dink daaraan dat julle self vreemdelinge was in Egipte. As die Uitlanders en die Reformers rumoer en opstand in die volkslewe bring, dan is dit Oom Paul wat maan tot lankmoedigheid, en dis hý wat die Reformers uitlewer aan Engeland om gestraf te word „My kom die wraak toe".

"Eer jou vader en jou moeder" - die Afrikaanse kind het tot heden toe nog grotendeels geweier om hulle vader en moeder te jy en jou.

„Want die sewende dag is die dag van die Here, jou God" - Sondagskenders verwys tot heden toe nog na die sogenaamde las van ledigheid wat „Oom Paul se Wet" op hulle lê.

Aandeel aan die landsbestuur is aan die eertydse ,kolonist" ontsê. Sy bestuursvermoëns is ontwikkel in diens van die kerk: predikant, kerkraad bestaande uit ouderlinge en diakens, versorging van armes, weduwees en wese, toepassing van kerktug óók op die predikant. Hier raak hulle gewoond aan 'n bykans Middeleeuse hiërargie. En as dit kom by republiekstigting, dan val dit ons op hoe die president telkens verskyn as 'n outydse rigter - patriarg, vader van sy volk. En dan val dit op dat elke Afrikaanse staatsleier van betekenis die mantel van patriarg omgehang het - hoof van sy volk, regeerder, profeet. Veral ons neentiende eeuse presidente, met Onse Jan van Kaapland inkluis, doen sterk aan as Bybelfigure uit die Ou Testament.

En elke huisvader is nog by ons hoof van sy gesin, godsdienstige hoof, beskikker oor sy eiendom. Hoe meer mens as Afrikaner die Ou-Testamentiese Bybel leer ken, hoe meer kom jy onder die indruk van die wonderbaarlike herhaling van die ou-ou geskiedenis in die lewe en lotgevalle van die nuwe soort mens aan die suiderpunt van Afrika - met tus- 
senin 'n tydsverloop van bykans 3,000 jaar en ruimtelike verskil van 'n paar duisend myl.

Wat ek hier wil sê is dat die styl, die sterkmakende krag in die lewe van ' $n$ volk die algemene opvatting is oor die aard van die bestaansoorsaak. In meer alledaagse woorde: Wat die volk dink oor sy eie ontstaan en bestaan, oor die skepping, oor die hiernamaals, dít bepaal watter soort volk ons het, dit bepaal die aard van daardie volk se kultuur, dít is sy lewenstyl as hy as volk uit daardie oortuiging leef.

Ons lewenstyl is Bybels, en dit het ons lewenstyl geword deurdat in die Afrikaner se vormingsjare, tot lank daarna, die aanraking en omgang met die Bybel baie intiem was, en in groot dele nog is. Watter beeld gee die Bybel van die skepping? Al wat is, is die maaksel van die Skepper, wat alles geskape het uit niks en met ' $n$ doel. Besonderlik die mens is geskep na sy ewebeeld. Vir Hom het Hy 'n volk gekies, en dié is gelei deur rigters en profete. Dié rigters en profete was heilig en 'n hand is nie aan hulle gelê nie. En dit is nog in hoofsaak die Afrikaanse wêreldbeeld: bo-oor alles die Skepper, die mens na sý ewebeeld, regeerders en kerkowerhede leiers by die genade van God. Vandaar die Afrikaner se ontsag vir owerheid, veral die voorman, en vir kerkowerheid. Het u al in ons geskiedenis gehoor van predikante en kerkleiers wat vermoor is deur hulle volksgenote? - Selfs Van der Kemp is in die lewe gelaat: Daarom is dit vir die Afrikaner so 'n wesenlike skok as sy kerkmanne afwyk van die volkspad. Daarom is dit ook dat selfs ons afwykendste staatsmanne aan die lewe gebly het - en as die eerste leiermoord, tot ons groot ontsetting, plaasvind is die dader nie 'n volksgenoot nie.

Ons kyk verder: Die Ou-Testamentiese Israel verval gedurig in sonde, dan volg volksrampe: droogtes, sprinkane, ontvoering, oorlog van buite. Dan word die volk opgeroep tot volksametrek, verootmoediging, erkenning van skuld en boetedoening en versoening ná biddae. Dis of ons ons eie volk se geskiedenis lees met ons herhaalde bid. en dankdae in dae van duisternis en nood. Maar soos vanouds word die stam van Levi afgesonder vir tempeldiens en die bring van offers. Die Leviete doen die werk waarvoor hulle uitverkore is, maar die res van Israel en Juda maak rook op die hoogtes, aanbid boomstamme, hoereer agter Baäl en Astarte aan. Die Leviete 
is mos daar om die band met die lewende God in stand te hou. En die Afrikaner, die tweede Israel? - Ons doen insgelyks. Die predikant word betaal om te bid, heilig te lewe, die sedes in stand te hou. Ons ander? Ons dra mini-rokkies, loop agter die sestigers aan, kweek ons hare en verkondig luidrugtig: "God is dood". Die predikante is mos daar om te bid. U sien, selfs in die negatiewe uitvloeisel uit die geloof aan 'n Enige, Ewige en Almagtige God, is die Afrikaanse lewenstyl Bybels. En waar kom ons Sieners vandaan? Mens dink aan Job, Jesaja, Esra.

Ons lewenstyl staan sterk gefundeer op die Bybel. Daaraan kan niemand twyfel nie. As laaste oorweging: die wyse waarop die gesinslewe van die Afrikaner nog die grondslag vorm van sy volkslewe.

Maar dit is nie die volle waarheid nie. Dit is so dat die Afrikaner nie hier outochtoon is nie, nie hier uit die aarde gegroei het uit niemand weet wat nie. Ons is ' $n$ historiese voortsetting van iets anders wat elders vandaan hierheen gekom het. Ons is naamlik die nasate van Nederlanders, Duitsers, Franse, later met 'n goeie bymengsel van Angelsaksers: Engelse, Skotte en Iere. As ons die Afrikaanse kultuurskat aandagtig ontleed: volksgeloof, volksgebruik, volksverhaal, stoflike kultuur, dan kry ons orals reste of oorblyfsels van die kultuurbesit van die ou volke waarin ons wortel. Ons kry selfs spore van invloed deur die vreemdelinge met wie ons in aanraking gekom het: hierlandse boorlinge, anderstaliges en anderskleurige intrekkers, slawe. Maar die inslag van vreemdes is selde rigtinggewend, selde oorsaak tot afwyking. Eerder is dit altyd versterking van wat reeds erfbesit was. In dié opsig werk ook die nuwe omgewing en nuwe landsomstandigheid heel dikwels mee tot versterking van stamvaderlike erfgoed. Laat ons één enkele Afrikaanse volkskenmerk betrag in hierdie verband.

In 'n belangrike opsig is die Afrikaanse volk nasate van die Europese Germaan: Frank, Sakser, Angel en Fries. Wanneer die lig van die geskiedenis op hierdie menssoort val, kry ons hom op die Europese vlaktes. Die vermoede is dat hy as soort ontwikkel het op die vlaktes verder ooswaarts, selfs op die Russiese steppeland. Dis dus 'n vlaktemens.

Een van die belangrikste kenmerke van die vlaktemens is sy verlange na die ruimte, die drang om te weet wat daar 
lê agter die ylblou berge wat aan die soom van die onmeetlike dof opgee. Die vlaktemens gee gehoor aan dié drang, en na mate hy verder vorentoe beweeg, gaan hy maar net dieper die vlakte in, en die bergsoom van sy wêreld veryl steeds verder, lokkend die onbekende in. Waar in ons geskiedenis kry jy nog 'n volk wat uit die Russiese vlaktes afsak oor Griekeland, Italië, die hele Noord- en Noordwes Europa, deur Spanje tot in Noord-Afrika, uit Europa oor die Nederlande, Skandinawië en Engeland na die nuwe wêreld in Amerika, Afrika(Suid), Australië en Asië? Soms verdwyn hulle soos ' $n$ droëloop in die woestynsand - dink maar aan die Wandale wat by Carthago spoorloos wegraak. Maar soms bring hulle nuwe groeipunte - Ysland, Amerika.

En ons self, ons eie soort, aan die eindpunt van Afrika. Dis bekend dat daar by die Afrikaner 'n geheimsinnige trekdrang is. Onwilliges noem dit treksug, bandeloosheid. Wesenlik is dit ' $n$ drang van die vlaktemens na die gesigeinders. En so kom ons oor die hele Kaapland, al met die Karoovlaktes langs oor die Vrystaat, Transvaal, Suidwes, Natal - tot ver anderkant die Wolkberge, Etosja en die Kunene tot by Lobitobaai en verder, selfs landuit tot by Commodora Rivadavia in Argentinië - so ver dat hulle selfs weer terug gehaal moes word. Hierdie drang na die onbekende wat so sterk uitslaan by die Germaanse mens, word gevoed deur die Bybelse agtergrond - ook Israel kom uit die woestynvlaktes. En is dit dan nie maar die teken van die skepsel wat die spore van sy Skepper soek nie? Is dit nie betekenisvol dat die maanreisigers juis moet spruit uit die nasate van die Indo-Germane nie?

Die vlaktemens, mens van die stilte. Die Afrikaner as kultuursoort is gevorm in die stilte van ons vlaktes - 'n versterking van sy erfgoed. Tot heden toe is dit nog kenmerkend dat ons van die stilte hou. Ons is rustig, ingetoë, wars van uiterlike vertoon. Wie dit nie wil glo nie, gaan kyk maar gerus na ons sogenaamde volksfeeste. Dit gaan alles kalm en bedaard, so onopwindend. Tog is dit nie, want die Afrikaner se gevoel is na binne gekeer. Maar dis dinge die wat ons volksleiers moet weet, wat organiseerders van volksfeeste aan eie liggaam moet voel om te kan slaag. Een voorbeeld: enkele jare gelede wou Pretoria 'n groot volksfees organiseer, met bier en gedans in die strate. Hoe het dit afgeloop? 'n Groue mislukking - want tradisioneel is die Afrikaner die 
mens uit die stilte wat nie hou van gejoel en straatrumoer nie. En die Afrikaner leef en bestaan uit sy wesensaard. Met ander woorde die Afrikaner het 'n tradisionele lewenstyl wat gegroei het uit drie duidelike bestanddele: sy omgang met die Bybel en sy Protestantse geloof; sy erfskat uit Europa; en sy aanraking met 'n nuwe land, nuwe omstandighede en nuwe mense.

Om Afrikaner te wees, is om uit dié drie bronne te put, daarna en daarvolgens te leef, om voortdurend die gronde van sy bestaan te vernuwe en te versterk. Sy lewenstyl, sy tradisionele lewenstyl is Afrikaans. Daarvolgens, daaruit en daardeur moet hy leef, of ondergaan.

En daarvoor is genade nodig.

Abel Coetzee.

Johannesburg. 